\title{
Produtividade Industrial no Espírito Santo: uma análise para a primeira década do século XXI ${ }^{1}$
}

Matheus Albergaria de Magalhães ${ }^{2}$

Anna Paula Lage Ribeiro ${ }^{3}$

\begin{abstract}
Resumo: O objetivo deste trabalho equivale a estudar a evolução de medidas de produtividade industrial no estado do Espírito Santo ao longo da primeira década do século XXI (período 2001/2009), bem como realizar uma comparação dessas medidas com resultados obtidos para outras Unidades da Federação (UFs) da região Sudeste e para o Brasil. Para tanto, fez-se uso de duas medidas alternativas de produtividade: a produtividade média do trabalho (PM) e a produtividade total dos fatores (PTF). De acordo com os resultados obtidos, foram constatados os seguintes fatos empíricos: (i) o estado do Espírito Santo apresentou, ao longo do período amostral considerado, um desempenho superior ao Brasil, independentemente da medida de produtividade utilizada; (ii) os índices de produtividade do estado demonstram um padrão positivo de comovimento com os índices referentes ao contexto nacional, ainda que apresentem um comportamento mais volátil, o que representa a possibilidade de uma retomada mais intensa do crescimento do estado no curto prazo; (iii) a comparação da produtividade do Espírito Santo com medidas de outros estados da região Sudeste revela que, anteriormente ao período da crise financeira mundial de 2007-2008, o estado apresentou um desempenho nitidamente superior às demais UFs, ao passo que, quando se considera o período posterior, o estado registrou o pior desempenho relativo; (iv) o desempenho da produtividade do trabalho, no caso estadual, parece estar condicionado principalmente ao nível de produção industrial. Dada a importância da produtividade para o crescimento de longo prazo, esses resultados são importantes no sentido de auxiliarem na formulação de políticas públicas que visem aumentar o bem-estar da sociedade.
\end{abstract}

Palavras-chave: macroeconomia; produtividade; Espírito Santo.

1 Os autores agradecem os comentários e sugestões de Ana Paula Vescovi e de dois pareceristas anônimos da Revista de Economia, que muito contribuíram para aprimorar a versão anterior do presente trabalho. Vale a ressalva usual de que erros e idiossincrasias remanescentes devem-se única e exclusivamente aos autores.

2 Coordenador de Estudos Econômicos, Rede de Estudos Macroeconômicos (MACRO), Instituto Jones dos Santos Neves (IJSN).

3 Mestranda em Engenharia Ambiental, Universidade Federal do Espírito Santo (UFES). 
JEL: C32, E23, O47

\title{
Industrial prductivity in Espirito Santo: a study of first decade of the $21^{\text {st }}$ century
}

\begin{abstract}
The main goal of this paper is to study the evolution of industrial productivity measures for the state of Espírito Santo over the 2001/2009 period and to compare these measures with results obtained for other states and Brazil. In doing so, two alternative productivity measures were employed: average labor productivity (LP) and total-factor-productivity (TFP). According to the results obtained, the following empirical patterns were identified: (i) over the sample period, the state of Espírito Santo has shown a better performance than Brazil, regardless of which productivity measure is considered; (ii) the State's productivity indexes display a positive comovement pattern with the Country's indexes, although they are more volatile, with this fact representing a possibility of a faster return to growth patterns over the short run; (iii) a comparison between the State's productivity indexes and other states' measures show that, in the pre-crisis period, the state of EspíritoSanto displayed a remarkably higher performance compared to other states, while the opposite seems to be true for the post-crisis period; (iv) in the case of labor productivity measures, the State's index seem to have its behavior conditioned mainly to the industrial production index. Given the importance of productivity over the long run, the results presented here are important in the sense of helping to estabilish public policies aiming at raising society's well-being.
\end{abstract}

Keywords: macroeconomics; productivity; Espírito Santo.

JEL: $\mathrm{C}_{32}, \mathrm{E} 23, \mathrm{O} 47$

\section{Introdução}

Entender a evolução da produtividade ao longo do tempo sempre constituiu uma das principais preocupações entre economistas e formuladores de política econômica. Em particular, uma compreensão acurada desse fenômeno pode constituir a resposta a uma questão fundamental em Economia: como aproveitar da melhor maneira possível os recursos escassos disponíveis? Recursos mais produtivos são, em geral, recursos que podem ser usados em menor montante, gerando maior economia em seu uso. Por conta disso, identificar focos de produtividade em uma economia pode equivaler a um uso mais eficiente dos recursos existentes.

Este trabalho tem o objetivo de estudar a evolução de medidas de produtividade no estado do Espírito Santo. Para tanto, será realizada uma análise 
comparativa de medidas de produtividade entre estados, com o objetivo de avaliar o desempenho da economia capixaba vis-à-vis as economias de outros estados brasileiros. A partir deste estudo inicial, quer-se apenas registrar alguns dos principais fatos empíricos relacionados à produtividade no estado, tendo como pano de fundo a produtividade do país como um todo ${ }^{2}$. Nesse sentido, o presente trabalho possui um caráter eminentemente descritivo. A exploração das possíveis causas e explicações para os padrões empíricos aqui descritos deve constituir objeto de estudos futuros.

Os resultados obtidos demonstram que a economia do estado apresentou um desempenho consideravelmente acima da média nacional ao longo do período amostral considerado. Apesar da produtividade ter apresentado uma queda pronunciada no período compreendido entre o final do ano de 2008 e início do ano de 2009, seu desempenho esteve acima da média durante a maior parte do ano de 2008. Por conta desses ganhos de produtividade verificados até recentemente, espera-se que a economia do Espírito Santo possa apresentar uma capacidade de recuperação mais rápida do que as demais economias estaduais, no caso de uma tendência de reversão no cenário econômico mundial.

Este trabalho está dividido da seguinte maneira: a segunda seção contém definições relacionadas às principais medidas de produtividade empregadas no trabalho, ao passo que a terceira seção descreve a base de dados e a metodologia empregadas na construção de índices de produtividade. A quarta seção contém os principais resultados obtidos, com ênfase na comparação do estado do Espírito Santo com o Brasil e demais estados da região Sudeste. Finalmente, na quinta seção são apresentadas as conclusões do trabalho e sugeridas algumas linhas de pesquisa futura.

\section{Definições de Produtividade}

Em termos gerais, produtividade pode ser definida como a relação entre a quantidade produzida e o volume de insumos necessários a essa produção, equivalendo a uma média de eficiência no processo produtivo.

Nesses moldes, a produtividade do trabalho (PL) pode ser definida como a razão entre as quantidades de produto e trabalho:

$$
\mathrm{PL}=\mathrm{P} / \mathrm{L}
$$

com o termo $P$ denotando produção, $L$ representando o fator trabalho e $P L$ equivalendo à produtividade do trabalho. Basicamente, essa medida equivale ao produto por trabalhador: quanto maior for essa razão, maior será a pro2 Os objetivos deste trabalho são semelhantes aos de Bonelli Fonseca (1998), que constroem diversas medidas de produtividade relacionadas a distintos setores da economia brasileira, tentando identificar os principais padrões empíricos inerentes a essas medidas. 
dutividade de uma dada unidade de análise.

Por outro lado, a produtividade total dos fatores (PTF) pode ser obtida a partir do resíduo de uma função de produção. No caso, considera-se uma função de produção do tipo

$$
Y(t)=A(t) F[K(t), L(t)]
$$

onde $Y(t)$ representa o montante de produto agregado, $K(t)$, o estoque de fator capital e $L(t)$, a quantidade de fator trabalho, com todas essas variáveis medidas em um dado instante $t$ de tempo. O termo $A(t)$ equivale a um índice do nível de tecnologia da economia.

Tomando logaritmos em ambos os lados de (2), bem como derivando a expressão resultante em relação ao tempo $(t)$, obtém-se:

$$
\dot{Y} / Y=\dot{A} / A+\left(\frac{A F_{K} K}{Y}\right)(\dot{K} / K)+\left(\frac{A F_{L} L}{Y}\right)(\dot{L} / L)
$$

Adicionalmente, supondo-se a existência de um mercado competitivo para os fatores de produção, assim como a ocorrência de retornos constantes de escala, pode-se obter a seguinte expressão: ${ }^{3}$

$$
\dot{Y} / /_{Y}=\dot{A} / A+\alpha(t)(\dot{K} / K)+(1-\alpha(t))(\dot{L} / L)
$$

onde $\alpha(t)$ representa a participação do fator capital na renda total, com [1 $\alpha(t)]$ representando, portanto, a participação do fator trabalho ${ }^{4}$. No caso de se

3 O fato do mercado de fatores de produção ser competitivo implica que o produto marginal de cada fator iguala seu preço, o que faz com que, em última instância, os termos $\left(A F_{K} K / Y\right)$ e $\left(A F_{L} L / Y\right)$ da expressão (B2) sejam equivalentes às parcelas de pagamento dos fatores capital e trabalho, respectivamente, em relação à renda total. Já a hipótese de retornos constantes de escala implica que as parcelas de pagamento dos fatores em relação à renda, quando somadas, igualam a unidade.

4 Vale notar que, ao se designar a participação do fator capital pelo termo $\alpha(t)$, considera-se a possibilidade de mudanças na participação dos fatores ao longo do tempo. Entretanto, no caso de uma função de produção do tipo Cobb-Douglas, a participação dos fatores é tida como constante. 
ter disponíveis dados relativos a quantidades $(Y, K$, e $L)$ e preços dos fatores (equivalentes às taxas de aluguel do capital e de salário do trabalho), chega-se a uma situação onde, de todas as variáveis da equação (4), a única que não pode ser medida diretamente é a taxa de crescimento do índice tecnológico da economia ( $A / A$ ). Colocando-se esta variável em função das demais:

$$
\dot{A} / /_{A}=\dot{Y} / Y-\alpha(t)(\dot{K} / K){ }^{(1-\alpha(t))}(\dot{L} / L)
$$

Ou seja, a taxa de crescimento de $A$ (PTF) nada mais é do que um "resíduo" da parte do crescimento do produto agregado que resta após serem subtraídas as taxas de crescimento dos fatores de produção (taxas estas, ponderadas por suas respectivas participações na renda agregada).

Ambos os conceitos apresentados possuem vantagens e desvantagens. A produtividade do trabalho apresenta a vantagem de simplicidade de cálculo: a partir de medidas de produção e fator trabalho, é possível calcular um índice que mensure produtividade. Por outro lado, há a possibilidade de que variações oriundas de fatores não incluídos nesse cálculo venham a afetar a medida construída. Por exemplo, variações não observáveis no fator capital podem afetar medidas de produtividade do trabalho, gerando a impressão de ocorrência de aumentos e/ou reduções de produtividade, mesmo quando esse não é o caso.

Essa limitação da PL acaba por constituir uma vantagem da PTF que, em teoria, busca considerar a importância dos principais fatores empregados no processo produtivo. Ainda assim, essa última medida apresenta uma desvantagem relacionada aos dados necessários a sua construção, uma vez que nem sempre é possível obter medidas que possam refletir adequadamente o fator capital, por exemplo. Adicionalmente, vale ressaltar que essa medida apresenta importantes desafios em termos de mensuração e estimação econométrica, o que acabou levando ao desenvolvimento de uma série de técnicas destinadas a facilitar esse processo nas últimas décadas ${ }^{5}$.

Em suma, ambas as medidas apresentam vantagens e desvantagens em sua conceituação e metodologia de construção, com seu uso conjunto devendo ser visto como uma tentativa de fornecer uma abordagem complementar sobre o tema, conforme os objetivos do presente trabalho.

Em termos operacionais, tem-se que as medidas de produtividade (média) do trabalho (PM) podem ser calculadas a partir da seguinte equação:

5 Para uma descrição da evolução histórica do conceito de PTF e de técnicas de mensuração a ele relacionadas, ver Griliches (1996). 


\section{$\mathrm{PM}=\mathrm{PF} / \mathrm{HP} \quad(6)$}

onde o termo $P F$ representa o índice de produção física do IBGE, enquanto o termo $H P$ representa o índice de horas pagas na indústria ${ }^{6}$.

Por sua vez, as medidas de produtividade total dos fatores foram calculadas a partir da metodologia proposta originalmente por Solow (1957):

$$
\Delta a_{t}=\boldsymbol{\Delta} p_{t}-\theta \boldsymbol{\Delta} e e_{t}-(1-\theta) \boldsymbol{\Delta} \boldsymbol{h}_{t}
$$

onde o termo $\Delta$ denota o operador de primeiras-diferenças, enquanto que letras minúsculas equivalem aos logaritmos naturais das séries em questão. De acordo com a fórmula acima, os termos $p$ e $h$ representam os logaritmos das variáveis produção industrial e horas pagas, ao passo que o termo ee denota o consumo industrial de energia elétrica. Por sua vez, o termo $\theta$ equivale à participação do fator capital na renda, ao passo que o termo $(1-\theta)$ equivale à participação do fator trabalho (assume-se retornos constantes à escala, no caso).

Conforme citado acima, no caso da PTF, a produtividade é vista como a parte residual de uma função de produção; ou seja, taxas de variação da PTF equivalem à diferença entre taxas de variação da produção industrial e taxas de variação dos insumos de produção, com esses insumos sendo ponderados por suas respectivas participações na renda ${ }^{7}$. No caso, a medida de horas pagas na indústria representa o fator trabalho, ao passo que a medida de consumo industrial de energia elétrica representa o fator capital ${ }^{8}$. As séries históricas de PTF foram obtidas a partir de um processo de integração das taxas de variação dessa variável, onde supõe-se que o período inicial equivale a um número índice com valor igual a $100^{9}$.

Adicionalmente, vale ressaltar que todas as séries de produtividade utilizadas neste trabalho foram dessazonalizadas a partir do método ARIMA X-12. No caso de alguns gráficos e tabelas específicos, foram utilizados os componentes

\footnotetext{
6 Resultados obtidos não mudam quando da utilização do índice de pessoal ocupado na indústria para representar o fator trabalho. Por conta disso e com o intuito de poupar espaço, optou-se pela exposição de resultados relacionados a medidas que fazem uso do índice de horas pagas, apenas.

$7 \quad$ Seguindo as recomendações de Kanczuk e Faria (2000) para o setor industrial brasileiro, considerou-se um valor de participação relativa do capital correspondente a 0,66 , o que faz com que a participação relativa do fator trabalho equivalha a 0,34, assumindo-se uma função de produção com retornos constantes de escala.

8 Devido ao fato de não existirem medidas equivalentes a estoques de capital para os setores industriais de distintos estados, optamos pelo uso de séries de consumo industrial de energia elétrica para representar os serviços do fator capital, em consonância com outros estudos aplicados, conforme é o caso de Burnside, Eichenbaum \& Rebelo (1995, 1996), por exemplo.
}

9 Leitores interessados em obter a base de dados empregada neste trabalho podem fazê-lo entrando em contato diretamente com os autores. 
cíclicos das séries, obtidos a partir do filtro Hodrick-Prescott (H-P) (Hodrick \& Prescott 1997), com o parâmetro de suavização desse filtro sendo fixado no valor de 14.400 , conforme prática usual no caso de estudos envolvendo dados mensais ${ }^{10}$.

\section{Base de Dados e Metodologia}

As variáveis utilizadas neste trabalho equivalem a dados referentes à produção e insumos industriais, basicamente. Em particular, optou-se pelo uso de dados da indústria, por conta da facilidade de obtenção dos mesmos ${ }^{11}$.

No caso, foram utilizadas as séries históricas de produção industrial, consumo industrial de energia elétrica e horas pagas na indústria para os estados da região Sudeste e para o Brasil $^{12}$. A fonte dos dados de produção industrial equivale à Pesquisa Industrial Mensal - Produção Física (PIM-PF), enquanto que os dados referentes a horas pagas na indústria são oriundos da Pesquisa Industrial Mensal de Emprego e Salários (PIMES), com ambas as pesquisas sendo elaboradas pelo Instituto Brasileiro de Geografia e Estatística (IBGE). As séries de consumo industrial de energia elétrica referentes ao estado são provenientes da Agência de Serviços Públicos de Energia do Estado do Espírito Santo (ASPE) e da Espírito Santo Centrais Elétricas S.A. (ESCELSA) ${ }^{13}$.

Neste trabalho, foram utilizadas duas medidas alternativas para representar a produtividade: uma medida de produtividade do trabalho, que leva em conta a produtividade média por trabalhador na indústria; e uma medida de produtividade total dos fatores (PTF), que considera a produtividade como uma parcela residual de uma função de produção, uma vez que são descontadas as participações relativas dos insumos capital (medido via consumo industrial de energia elétrica) e trabalho (medido via horas pagas na indústria). Essas medidas alternativas são utilizadas no sentido de fornecerem resultados robustos à análise presente.

10 O filtro H-P equivale a um filtro linear usado para extração do componente de longo prazo de uma série. A partir da subtração desse componente da série original, é possível obter o componente cíclico da série. Maiores detalhes sobre esse filtro podem ser encontrados no Apêndice $B$ do presente trabalho.

11 Exemplos de outros estudos que também fazem uso de dados industriais para analisar a evolução da produtividade no curto prazo são Burnside, Eichenbaum \& Rebelo (1995, 1996), Bonelli \& Fonseca (1998), Kanczuk \& Faria (2000) e Magalhães (2010).

12 Vale a ressalva de que existem diferenças na composição dos índices de produção industrial de acordo com a UF considerada, uma vez que o IBGE considera indústrias que representem pelo menos $80 \%$ da indústria local (média do triênio 1998-200o) quando da construção desses índices. Assim, o índice referente ao estado de São Paulo é composto por 20 (vinte) setores industriais, enquanto que ambos os índices referentes aos estados do Rio de Janeiro e Minas Gerais são compostos por 13 (treze) setores. O estado do Espírito Santo, por sua vez, é composto por 5 (cinco) setores, apenas. (Indicadores Conjunturais da Indústria 2004). É provável que essas diferenças de composição possam vir a afetar os resultados de análises envolvendo comparações entre esses indicadores. Fica a sugestão de que a pesquisa futura busque verificar essas diferenças a partir da elaboração de estudos envolvendo microdados, nos moldes sugeridos por Bartelsman e Doms (2000), por exemplo.

13 O Apêndice A do trabalho apresenta estatísticas descritivas (Tabela A1) e gráficos das principais variáveis empregadas na análise (Gráficos A1-A3). 


\section{Resultados}

Os gráficos 1 e 2 mostram a evolução das medidas de produtividade construídas para o estado do Espírito Santo ao longo do período compreendido entre os meses de fevereiro de 2001 e maio de 2009, assim como medidas similares construídas para o Brasil para fins de comparação (séries expressas em números índice, com fevereiro de $2001=100$ ). O gráfico 1 apresenta a evolução temporal de medidas de produtividade do trabalho, enquanto que o gráfico 2 apresenta a evolução de medidas de produtividade total dos fatores.

De acordo com o gráfico 1, em termos de produtividade do trabalho, o estado do Espírito Santo manteve-se acima do Brasil durante a maior parte do período de análise considerado, embora tenha apresentado oscilações nesse período. A partir do final de 2008, a produtividade do trabalho caiu tanto no Espírito Santo quanto no Brasil. Apesar dessa queda ter sido mais pronunciada no estado em comparação ao país (quedas de -37,4\% e -21,4\%, respectivamente, para o estado e para o país), vale notar que houve uma recuperação em ambos os casos a partir do ano de $2009(+17,7 \%$ e $+16,3 \%$, respectivamente para o estado e o país), com o Espírito Santo continuando com uma trajetória superior em relação ao caso nacional.

GRÁFICO 1. PRODUTIVIDADE DO TRABALHO - BRASIL E ESPÍRITO SANTOFEV.2001/MAIO. 2009

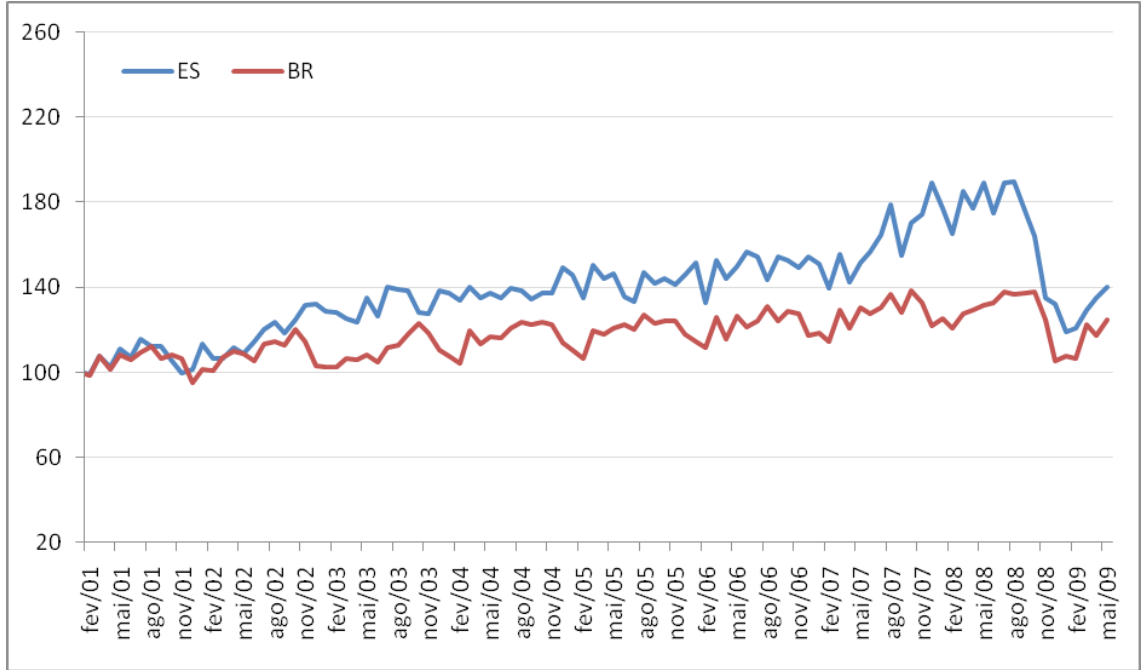

Elaboração: Cálculos dos Autores.

FONTE: Pesquisa Industrial Mensal - Produção Física (PIM-PF) e Pesquisa Industrial Mensal de Empregos e Salários (PIMES), ambas do IBGE. 
No caso do gráfico 2, que exibe a evolução da produtividade total dos fatores (PTF) para o Espírito Santo e o Brasil ao longo do período compreendido entre fevereiro de 2001 e dezembro de 2008 , o estado ainda apresenta um padrão superior em relação ao país durante a maior parte do período analisado, embora as diferenças sejam mais marcantes ${ }^{14}$. No caso dessa medida de produtividade específica, o estado do Espírito Santo apresenta um nítido descolamento em relação à trajetória nacional, chegando a apresentar um desempenho cerca de mais de duas vezes superior em relação ao país, no caso de certos períodos, conforme é o caso do período compreendido entre agosto de 2007 e agosto de 2008, por exemplo.

GRÁFICO 2. PRODUTIVIDADE TOTAL DOS FATORES - BRASIL E ESPÍRITO SANTO. FEV.2001/FEV.2009

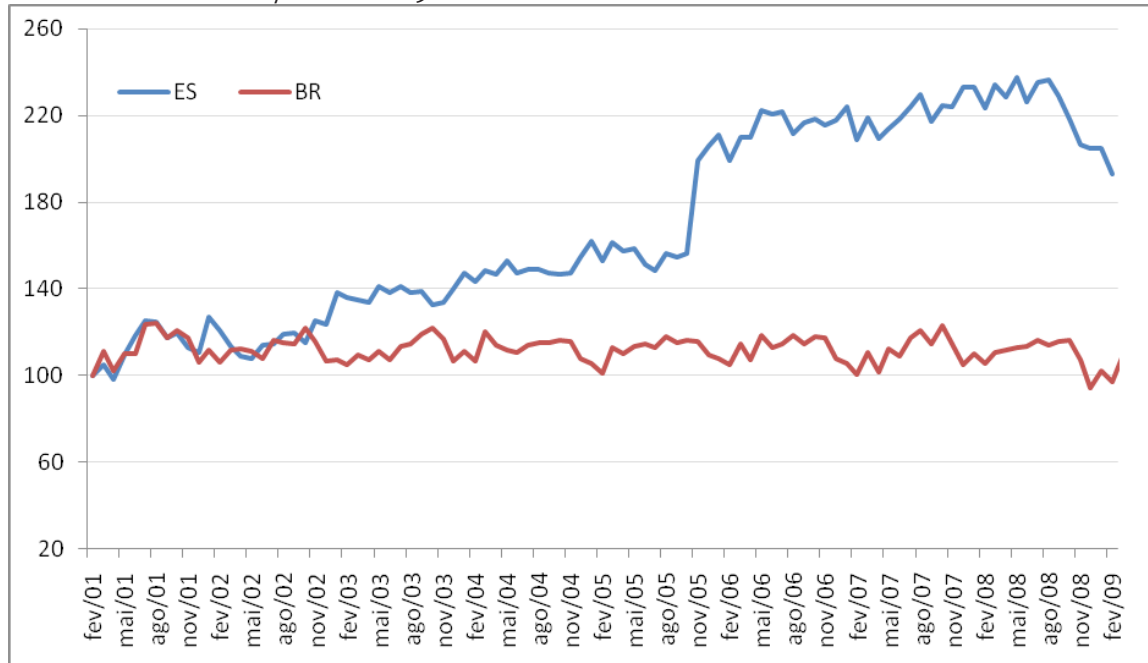

Elaboração: Cálculos dos Autores.

FONTE: Pesquisa Industrial Mensal - Produção Física (PIM-PF), Pesquisa Industrial Mensal de Empregos e Salários (PIMES) (IBGE), Agência de Serviços Públicos de Energia do Estado do Espírito Santo (ASPE), Espírito Santo Centrais Elétricas S.A. (ESCELSA) e Eletrobrás.

Em particular, vale à pena notar que, em termos de PTF, o estado não apenas apresenta uma trajetória ascendente ao longo do tempo, assim como ocorre uma nítida mudança de patamar na trajetória dessa variável a partir do final do ano de 2005. Quando da análise da evolução temporal das medidas componentes da PTF estadual, é possível notar uma nítida queda no consumo industrial de energia elétrica nesse período, fato que pode ser tido, a princí-

14 No caso de medidas de PTF, o período amostral ficou restrito até o mês de dezembro de 2008, devido ao fato desse mês ser o último período com dados de consumo industrial de energia elétrica disponíveis. Os autores agradecem a Alexandre Souza, da ASPE, pelo fornecimento de dados de consumo de energia elétrica relacionados ao estado do Espírito Santo. 
pio, como responsável por esse aumento de produtividade, uma vez que uma queda nessa variável tende a aumentar o índice de produtividade mensurado de acordo com a metodologia supracitada.

O gráfico 3 abaixo demonstra esse ponto de maneira mais clara, ao descrever as trajetórias da PTF e dos insumos de produção ao longo do período considerado $($ fev.2001 $=100)$.

GRÁFICO 3. PRODUTIVIDADE TOTAL DOS FATORES -ESPÍRITO SANTO. FEV.2001/FEV.2009

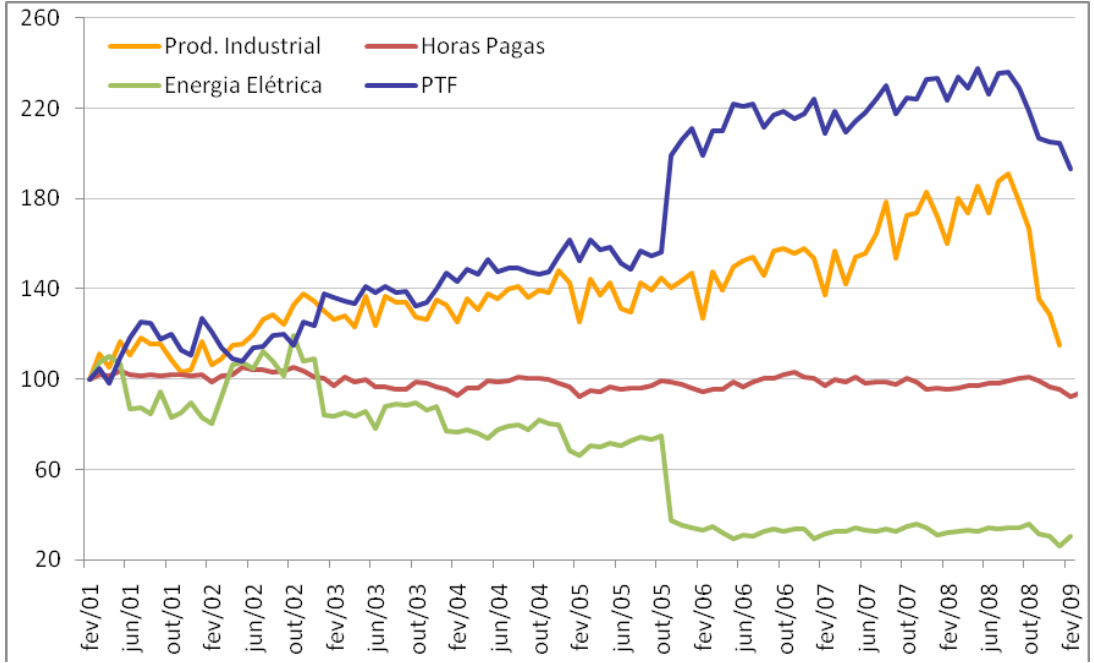

Elaboração: Cálculos dos Autores.

FONTE: Pesquisa Industrial Mensal - Produção Física (PIM-PF), Pesquisa Industrial Mensal de Empregos e Salários (PIMES) (IBGE), Agência de Serviços Públicos de Energia do Estado do Espírito Santo (ASPE) e Espírito Santo Centrais Elétricas S.A. (ESCELSA).

Conforme é possível notar, a trajetória da PTF estadual segue, de maneira aproximada, a trajetória da produção industrial. Por sua vez, o índice de horas pagas apresenta uma trajetória relativamente constante ao longo do período considerado, enquanto que o consumo industrial de energia elétrica apresenta um padrão descendente, com uma queda substancial a partir do final do ano de $2005^{15}$.

Os gráficos 4 e 5 apresentam as taxas de variação percentual dos componentes cíclicos das medidas de produtividade consideradas (obtidos via filtro H-P), tanto para o caso estadual quanto para o caso nacional.

15 Embora não seja o objetivo do presente trabalho explorar de forma detalhada as possíveis causas dessa mudança, fica a sugestão de que a pesquisa futura venha a fazê-lo. 
GRÁFICO 4 . PRODUTIVIDADE DO TRABALHO - BRASIL E ESPÍRITO SANTO. COMPONENTES CÍCLICOS

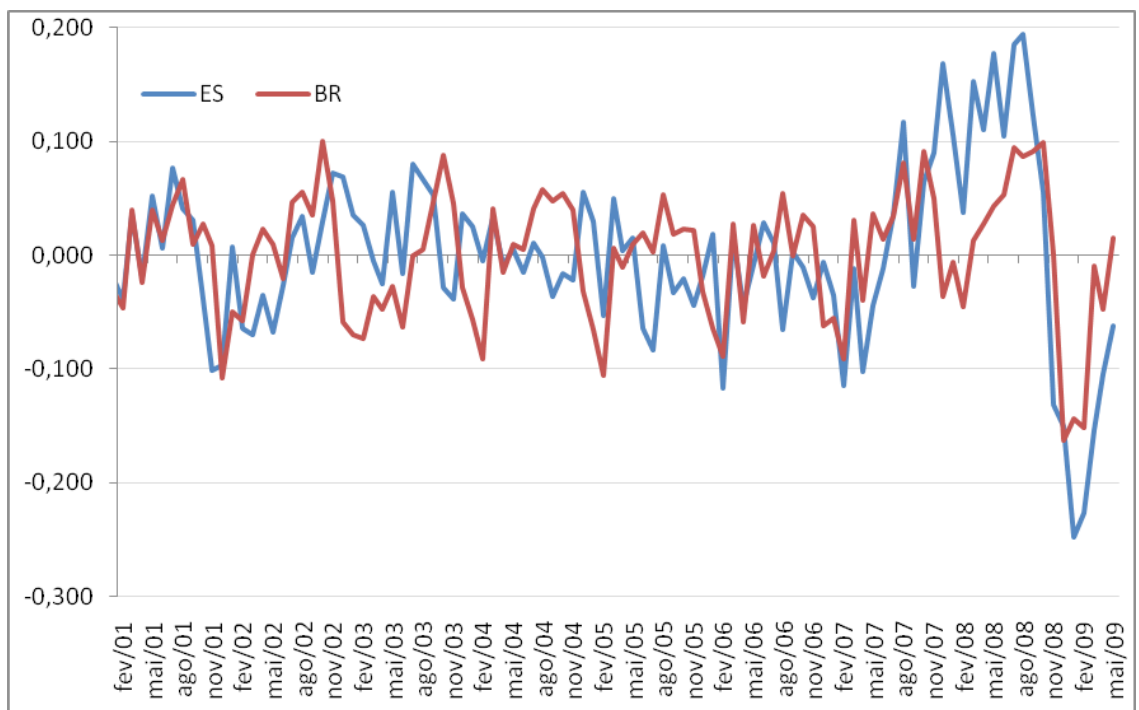

Elaboração: Cálculos dos Autores.

FONTE: Pesquisa Industrial Mensal - Produção Física (PIM-PF) e Pesquisa Industrial Mensal de Empregos e Salários (PIMES), ambas do IBGE.

Nota: Os componentes cíclicos das séries foram obtidos a partir do filtro Hodrick-Prescott, com parâmetro de suavização $\lambda=14.400$ (dados mensais). 
GRÁFICO 5 . PRODUTIVIDADE TOTAL DOS FATORES - BRASIL E ESPÍRITO SANTO. COMPONENTES CÍCLICOS

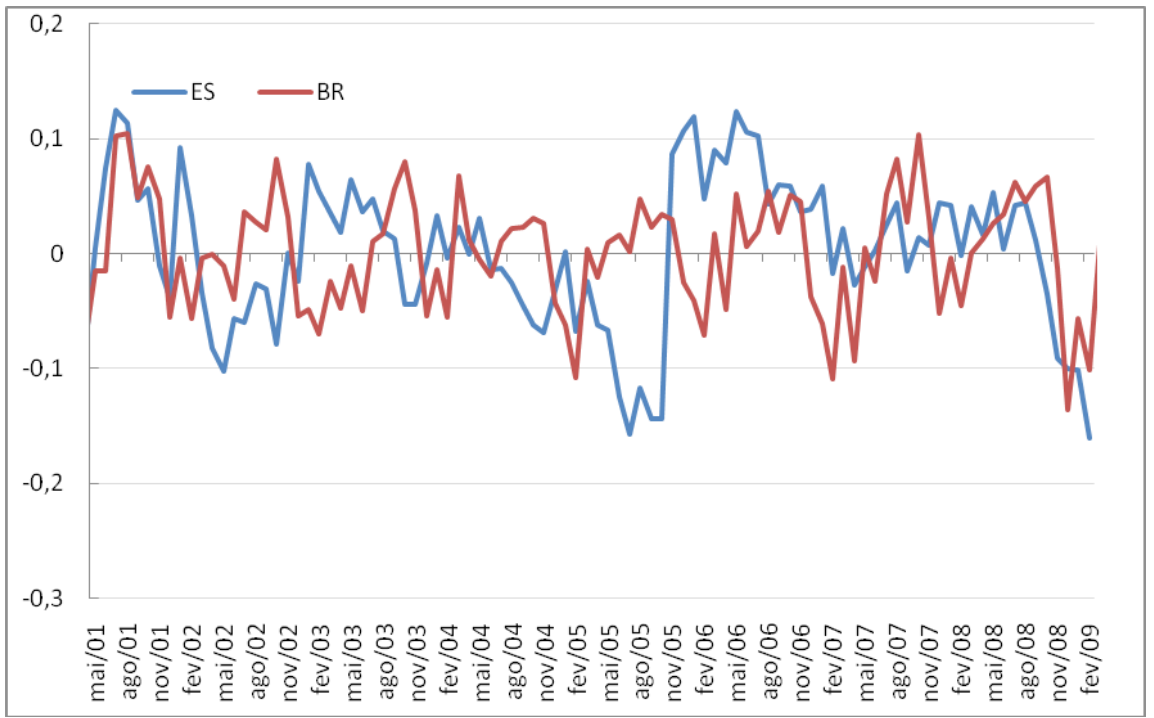

Elaboração: Cálculos dos Autores.

FONTE: Pesquisa Industrial Mensal - Produção Física (PIM-PF), Pesquisa Industrial Mensal de Empregos e Salários (PIMES) (IBGE), Agência de Serviços Públicos de Energia do Estado do Espírito Santo (ASPE), Espírito Santo Centrais Elétricas S.A. (ESCELSA) e Eletrobrás.

Nota: Os componentes cíclicos das séries foram obtidos a partir do filtro Hodrick-Prescott, com parâmetro de suavização $\lambda=14.400$ (dados mensais).

Dois fatos básicos emergem a partir da inspeção dos gráficos acima. Em primeiro lugar, a amplitude das flutuações cíclicas das medidas de produtividade estadual é nitidamente maior do que no caso das medidas de produtividade nacional (os desvios padrão das medidas de produtividade do trabalho e PTF para o Espírito Santo são 7,6\% e 6,6\%, enquanto que, para o Brasil, esses valores são $5,6 \%$ e 5,1\%). Tanto as variações positivas quanto as variações negativas das medidas de produtividade consideradas são maiores no caso estadual do que no caso nacional. Se, por um lado, isso demonstra que as contrações de produtividade são mais sentidas no estado do que no país, por outro revela a possibilidade de uma recuperação mais rápida dessas medidas, no caso de uma retomada do crescimento. Esse último ponto fica especialmente evidenciado no caso do gráfico 4, referente à produtividade do trabalho. Nesse caso, é possível notar que, apesar do estado do Espírito Santo ter sofrido uma queda mais severa de produtividade, sua recuperação também foi mais intensa durante os primeiros meses do ano de 2009. 
Em segundo lugar, há um certo grau de associação entre movimentos cíclicos de medidas de produtividade do estado e do país como um todo, conforme exposto na Tabela 1 abaixo. Em particular, coeficientes de correlação calculados para cada par de medidas de produtividade (PM ou PTF) revelam um grau de associação linear positivo entre as séries (coeficientes de correlação de 0,66 para séries de produtividade do trabalho e de o,33 para séries de PTF), com ambos os coeficientes sendo estatisticamente significativos ao nível de $1 \%$ de significância.

TABELA 1 . COEFICIENTES DE CORRELAÇÃO ENTRE COMPONENTES CÍCLICOS DE MEDIDAS DE PRODUTIVIDADE DA INDÚSTRIA BRASILEIRA E ESPÍRITO SANTENSE

\begin{tabular}{l|c|c}
\hline $\begin{array}{l}\text { Medida de Produtivi- } \\
\text { dade }\end{array}$ & $\begin{array}{c}\text { Produtividade } \\
\text { do Trabalho }\end{array}$ & $\begin{array}{c}\text { Produtividade To- } \\
\text { tal dos Fatores }\end{array}$ \\
\hline $\begin{array}{l}\text { Coeficiente de Corre- } \\
\text { lação Estimado }\end{array}$ & $0,656^{* * *}$ & $0,329^{* * *}$ \\
\hline
\end{tabular}

Elaboração: Cálculos dos Autores.

FONTE: Pesquisa Industrial Mensal - Produção Física (PIM-PF), Pesquisa Industrial Mensal de Empregos e Salários (PIMES) (IBGE), Agência de Serviços Públicos de Energia do Estado do Espírito Santo (ASPE), Espírito Santo Centrais Elétricas S.A. (ESCELSA) e Eletrobrás.

Notas: (a); Os componentes cíclicos das séries foram obtidos a partir do filtro Hodrick-Prescott, com parâmetro de suavização $\lambda=14.400$ (dados mensais). (b); Os períodos de comparação equivalem aos períodos amostrais comuns das séries, indo de fevereiro a dezembro de 2000 a maio de 2009 (produtividade do trabalho) e fevereiro de 2001 a dezembro de 2008 (produtividade total dos fatores). (c); O termo ${ }^{* * *}$ ) denota significância estatística dos coeficientes de correlação estimados ao nível de $1 \%$ de significância.

Em termos de comparação com os demais estados da região Sudeste, são apresentados alguns resultados abaixo. No gráfico 6, é exposta a evolução temporal de medidas de produtividade do trabalho para os quatro estados dessa região $(\text { fev.2001 }=100)^{16}$. De acordo com os resultados contidos nesse gráfico, é possível notar que a economia do estado do Espírito Santo apresenta, a partir do final do ano de 2002, um resultado superior em relação aos demais estados da região, mantendo esse desempenho positivo até o final do ano de 2008. Ou seja, em um período de aproximadamente dez anos, o Espírito Santo ultrapassou os demais estados da região Sudeste, em termos de produtividade ${ }^{17}$.

16 A análise ficou restrita a medidas de produtividade do trabalho apenas, por conta de limitações na obtenção de dados de consumo industrial de energia elétrica para São Paulo, Rio de Janeiro e Minas Gerais, o que impossibilitou a construção de medidas de PTF para esses estados.

17 À primeira vista, este fato constitui uma evidência favorável à lei de Kaldor-Verdoorn, segundo a qual, ocorre uma tendência de crescimento da produtividade de um país ou região à medida em que aumenta sua produção. No caso, o aumento da produção industrial estadual pode ser constatado a partir da evolução temporal desse índice, conforme exposto no gráfico 3 acima. Entretanto, ainda parecem necessárias confirmações adicionais desse padrão a partir de exercícios empíricos visando comprovar sua robustez. Fica essa sugestão 
GRÁFICO 6 . PRODUTIVIDADE DO TRABALHO - REGIÃO SUDESTE. DEZ.200o/ MAIO .2009

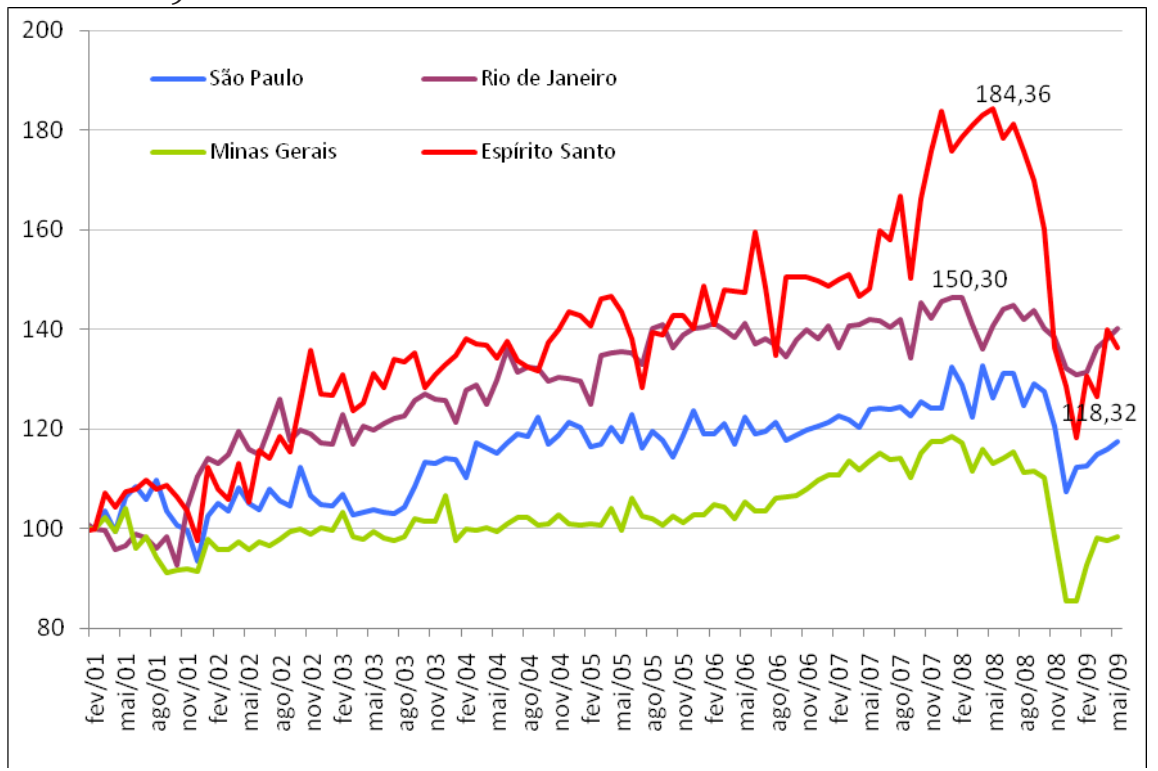

Elaboração: Cálculos dos Autores.

FONTE: Pesquisa Industrial Mensal - Produção Física (PIM-PF) e Pesquisa Industrial Mensal de Empregos e Salários (PIMES), ambas do IBGE.

O gráfico 7 exibe taxas de variação percentual da produtividade do trabalho para os estados da região Sudeste, assim como para o Brasil, no caso de dois períodos amostrais específicos: janeiro a agosto de 2008 e setembro de 2008 a maio de 2009. O objetivo básico desse gráfico é verificar os possíveis impactos da crise financeira de 2007-2008 sobre a produtividade do país e dos estados selecionados. 
GRÁFICO 7 . VARIAÇÃO PERCENTUAL DA PRODUTIVIDADE DO TRABALHO DOS ESTADOS DA REGIÃO SUDESTE PARA PERÍODOS SELECIONADOS

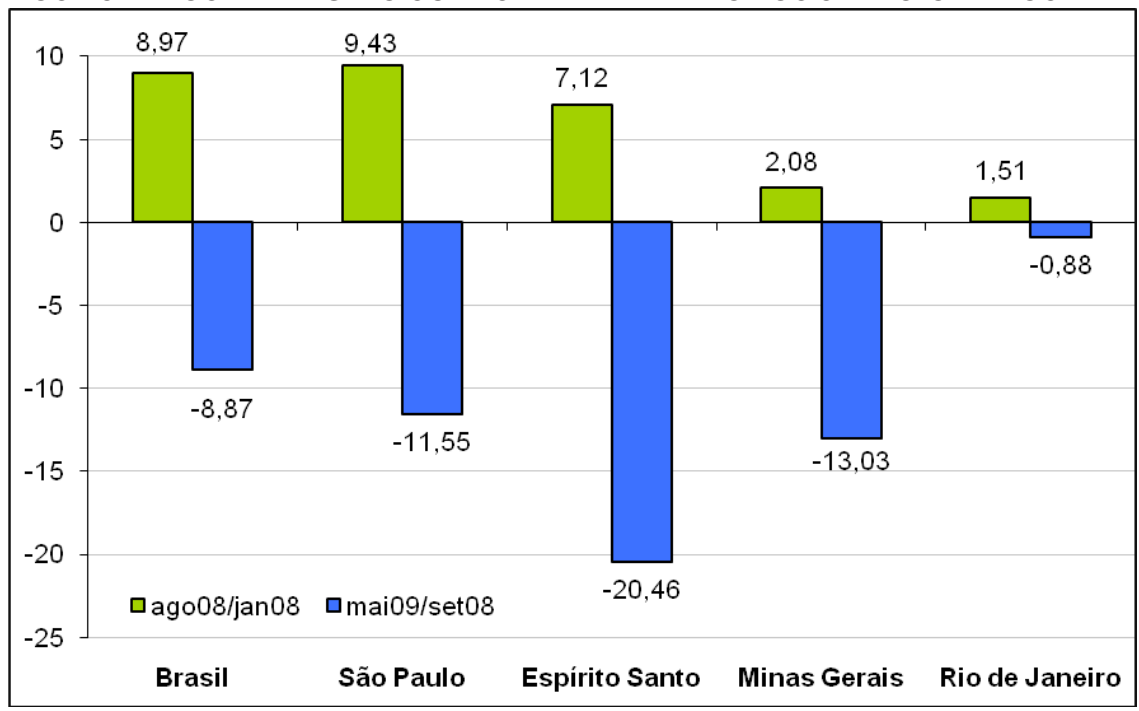

Elaboração: Cálculos dos Autores.

FONTE: Pesquisa Industrial Mensal - Produção Física (PIM-PF) e Pesquisa Industrial Mensal de Empregos e Salários (PIMES), ambas do IBGE.

No caso desse gráfico, é possível notar que, no período anterior à eclosão da crise no país (janeiro-agosto de 2008), tanto o Brasil quanto os estados da região Sudeste vinham apresentando taxas positivas de crescimento da produtividade do trabalho. Em particular, o estado do Espírito Santo apresentou, ao longo desse período, o segundo melhor desempenho na região Sudeste, com uma taxa de crescimento de 7,12\% no período, ficando atrás apenas do estado de São Paulo, que apresentou nesse período um crescimento da produtividade do trabalho de 9,43\%, um valor acima daquele verificado para o Brasil (crescimento de 8,97\%).

Por outro lado, durante o período compreendido entre os meses de setembro de 2008 e maio de 2009, todos os estados, bem como o país, apresentaram taxas negativas de crescimento da produtividade industrial. Assim, enquanto o Brasil apresentou um decréscimo de $-8,87 \%$ no período, verifica-se a ocorrência de decréscimos de -0,88\%, -11,55\%, -13,03\% para os estados do Rio de Janeiro, São Paulo e Minas Gerais. O estado do Espírito Santo, por sua vez, apresenta o pior desempenho nesse período: uma variação negativa de -20,46\%. Esse fato, juntamente com os dados relacionados ao gráfico 6, demonstram que, apesar do Espírito Santo ter apresentado um desempenho acima da média ao longo da maior parte dos períodos amostrais considerados, o estado também tende a apresentar um desempenho acima da média durante 
períodos de contração econômica, com a produtividade do trabalho caindo em um ritmo mais acentuado do que os demais estados da região Sudeste.

Esse último ponto é confirmado pelo gráfico 8, que apresenta a evolução dos componentes cíclicos das séries de produtividade do trabalho. Neste gráfico, são enfatizadas as oscilações de curto prazo das séries consideradas. Conforme é possível notar a partir da inspeção desse gráfico e da Tabela 2 abaixo, o estado apresenta a maior volatilidade dentre todas as séries consideradas, com um desvio-padrão de 9,1\%, um valor aproximadamente duas vezes e meia superior aos desvios-padrão dos estados de São Paulo e Rio de Janeiro, por exemplo (desvios padrão de 3,98\% e 3,64\%, respectivamente).

GRÁFICO 8 . PRODUTIVIDADE DO TRABALHO - REGIÃO SUDESTE. COMPONENTES CÍCLICOS

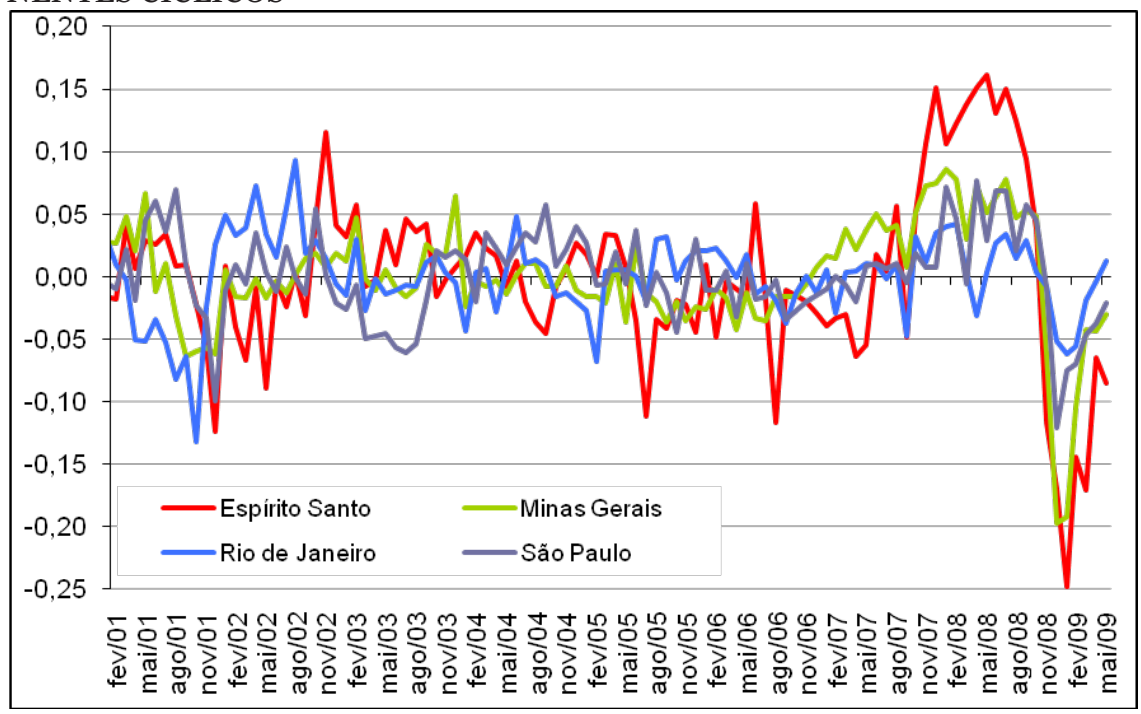

Elaboração: Cálculos dos Autores.

FONTE: Pesquisa Industrial Mensal - Produção Física (PIM-PF) e Pesquisa Industrial Mensal de Empregos e Salários (PIMES), ambas do IBGE.

Nota: Os componentes cíclicos das séries foram obtidos a partir do filtro Hodrick-Prescott, com parâmetro de suavização $\lambda=14.400$ (dados mensais). 
TABELA 2. DESVIOS-PADRÃO DOS COMPONENTES CÍCLICOS DE MEDIDAS DE PRODUTIVIDADE DO TRABALHO NA INDÚSTRIA DOS ESTADOS DA REGIÃO SUDESTE

\begin{tabular}{c|c|c|c|c}
\hline Estado & $\begin{array}{c}\text { Espírito } \\
\text { Santo }\end{array}$ & $\begin{array}{c}\text { Minas } \\
\text { Gerais }\end{array}$ & $\begin{array}{c}\text { Rio de } \\
\text { Janeiro }\end{array}$ & São Paulo \\
\hline Desvio-Padrão & $\mathbf{9 , 0 9 8}$ & $\mathbf{4 , 7 6 7}$ & $\mathbf{3 , 6 4 3}$ & $\mathbf{3 , 9 7 5}$ \\
\hline
\end{tabular}

Elaboração: Cálculos dos Autores.

FONTE: Pesquisa Industrial Mensal - Produção Física (PIM-PF) e Pesquisa Industrial Mensal de Empregos e Salários (PIMES) (IBGE).

Notas: (a) Os componentes cíclicos das séries foram obtidos a partir do filtro Hodrick-Prescott, com parâmetro de suavização $\lambda=14.400$ (dados mensais). (b) O período de comparação equivale aos período amostral comum das séries, indo de fevereiro a dezembro de 2000 até maio de 2009.

Uma questão interessante a ser respondida no presente contexto é a seguinte: quais são os fatores inerentes à queda recente da produtividade do trabalho no estado e no país? Os gráficos 9 a 11 buscam responder essa questão.

No caso do gráfico 9, é apresentada a evolução da produtividade do trabalho para o Brasil e o Espírito Santo ao longo do período compreendido entre os anos de 2002 e 2009 (dados disponíveis até maio). Em primeiro lugar, os dados desse gráfico demonstram que, em termos anuais, a produtividade do estado esteve acima da produtividade do país para a maioria dos períodos considerados. A exceção fica por conta do período final da amostra (dados disponíveis até maio de 2009) e do ano de 2004, onde o estado cresceu cerca de $5 \%$, enquanto que o país apresentou um crescimento em torno de $6 \%$. Em segundo lugar, esses dados também demonstram que, em termos de dados anuais, o estado apresentou uma queda na produtividade do trabalho correspondente acerca de 2,5 vezes a queda ocorrida no caso nacional (quedas de $-10,24 \%$ e -24,78\% para Brasil e Espírito Santo, respectivamente). 
GRÁFICO 9 . PRODUTIVIDADE DO TRABALHO. VARIAÇÃO PERCENTUAL EM RELAÇÃO AO PERÍODO ANTERIOR

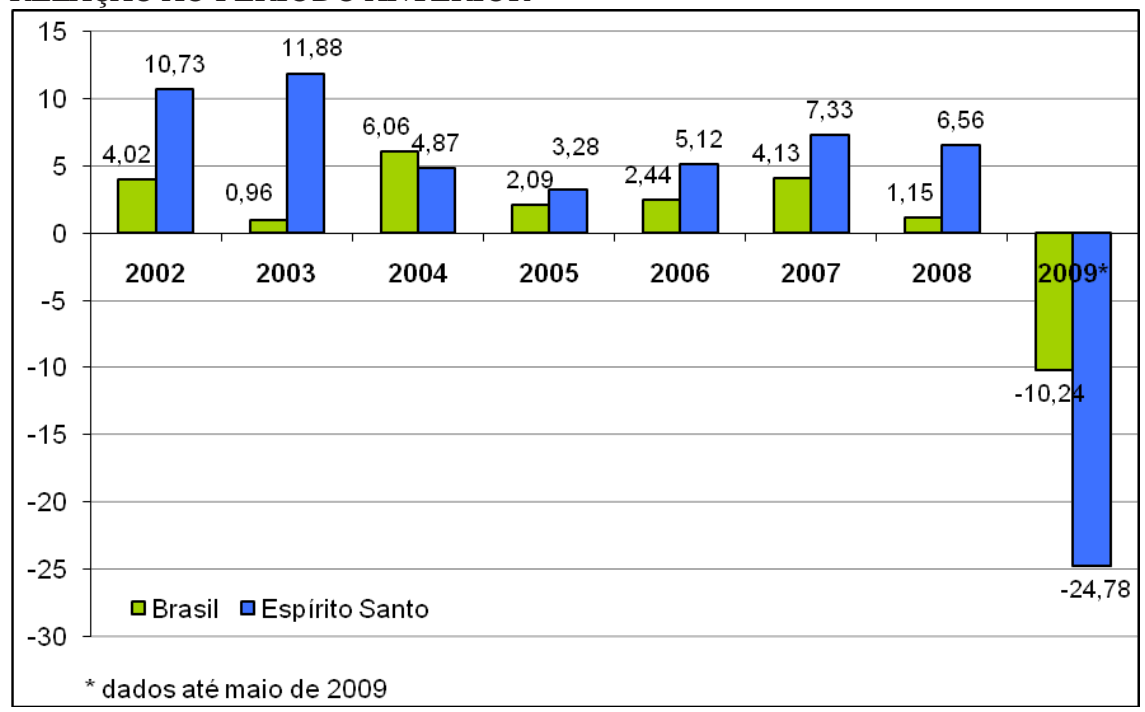

Elaboração: Cálculos dos Autores.

FONTE Pesquisa Industrial Mensal - Produção Física (PIM-PF) e Pesquisa Industrial Mensal de Empregos e Salários (PIMES), ambas do IBGE.

Os gráficos 10 e 11 ajudam a compreender os fatores relacionados a essa queda na produtividade do trabalho.

No caso do gráfico 10, são expostas as taxas anuais de variação da produção industrial para Brasil e Espírito Santo. Este gráfico demonstra que os resultados relacionados ao desempenho da produtividade, expostos no gráfico 9 , devem-se principalmente ao desempenho do índice de produção industrial do estado, que também permaneceu acima do índice nacional para a grande maioria dos anos considerados, com a exceção ficando para os anos de 2004, 2005 e 2009, apenas. 
GRÁFICO 10. PRODUÇÃO INDUSTRIAL. VARIAÇÃO PERCENTUAL EM RELAÇÃO AO PERÍODO ANTERIOR

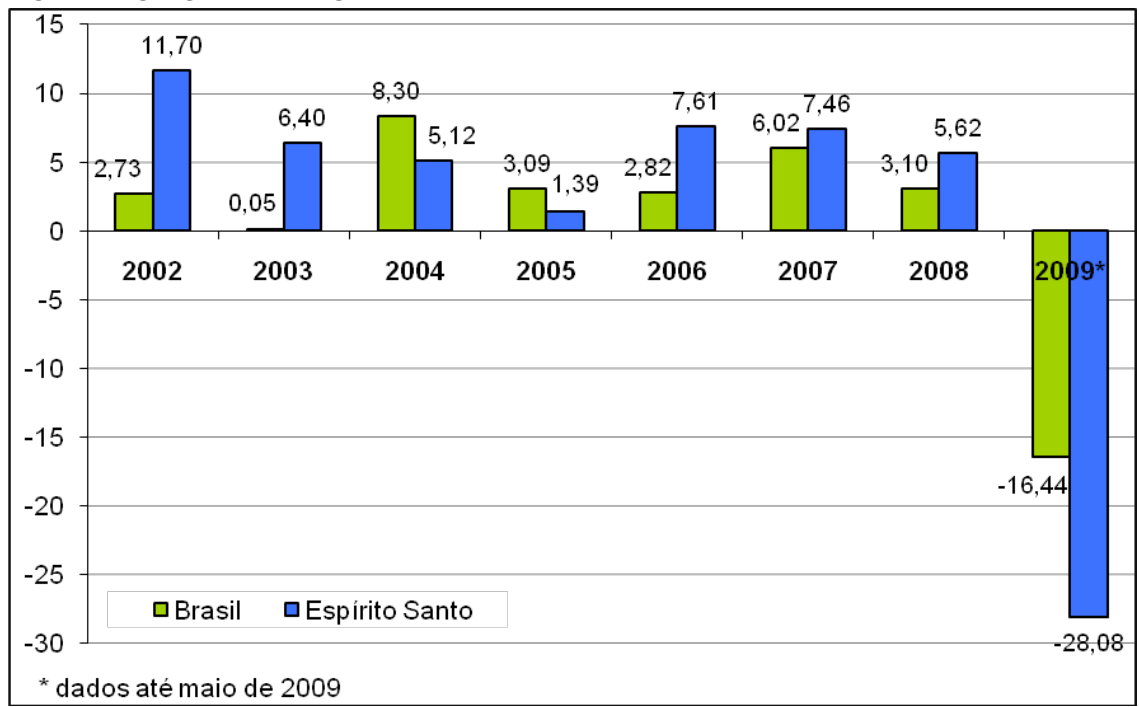

Elaboração: Cálculos dos Autores.

FONTE: Pesquisa Industrial Mensal - Produção Física (PIM-PF) (IBGE).

Por sua vez, o gráfico 11 apresenta as taxas de variação das horas pagas na indústria para o mesmo período de análise. Embora tenha havido certo grau de variação no caso das horas pagas, essa variação é visivelmente menor do que a variação reportada para índices de produção industrial. 
GRÁFICO 11 . HORAS PAGAS. VARIAÇÃO PERCENTUAL EM RELAÇÃO AO PERÍODO ANTERIOR

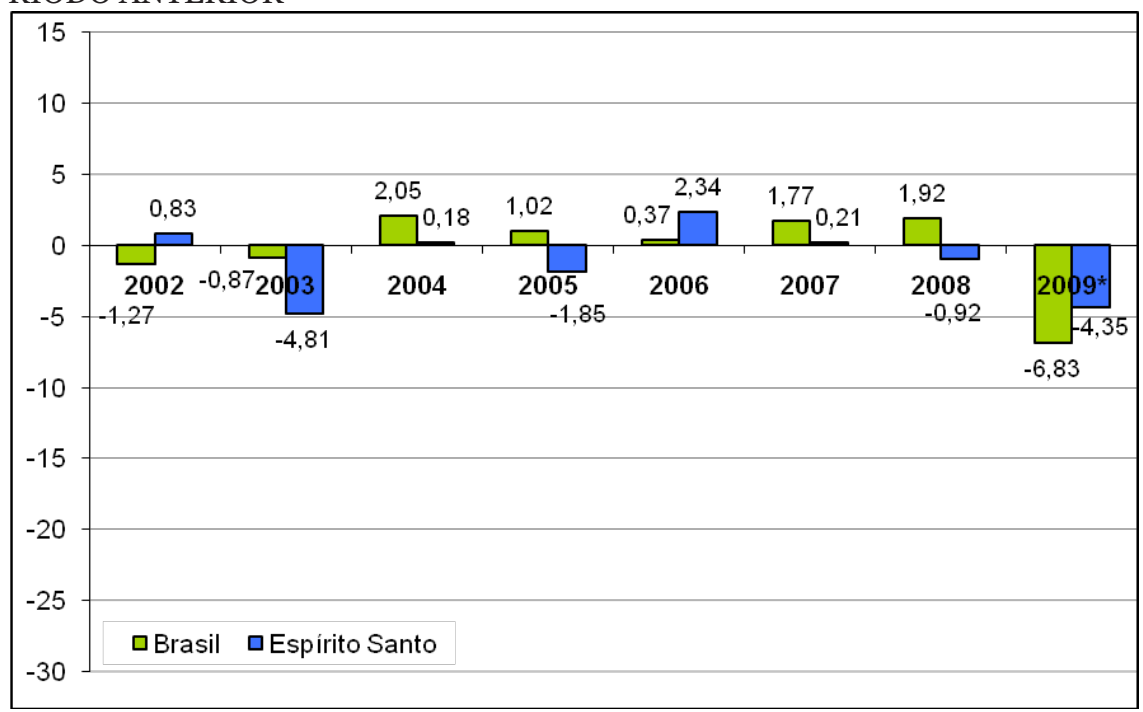

Elaboração: Cálculos dos Autores.

FONTE: Pesquisa Industrial Mensal de Empregos e Salários (PIMES) (IBGE).

Assim, é possível concluir que, ao longo do perído amostral considerado (2002-2009), o desempenho da produtividade do trabalho, tanto no caso estadual quanto nacional, foi afetado principalmente por conta do desempenho do índice de produção industrial. Logo, fatores que afetem os índices de produção industrial tenderão a afetar a produtividade do trabalho no país e no estado.

\section{Considerações finais}

Este trabalho buscou apresentar uma caracterização empírica inicial de medidas de produtividade no estado do Espírito Santo, bem como realizar uma comparação dessas medidas com medidas relacionadas a outras UFs da região Sudeste e ao Brasil como um todo.

Os resultados obtidos revelam os seguintes padrões empíricos:

Em termos de medidas expressas em números-índice, o estado do Espírito Santo apresentou um desempenho superior ao Brasil ao longo do período 2003-2009, independentemente da medida de produtividade considerada (produtividade do trabalho ou PTF). 
Em termos de variações percentuais de componentes cíclicos, as séries de produtividade do estado do Espírito Santo, apesar de apresentarem um padrão positivo de comovimento com as séries referentes ao caso nacional, também apresentam oscilações mais amplas no curto prazo. Se, por um lado, esse fato ressalta um padrão mais volátil da produtividade estadual, por outro, também revela a possibilidade de uma retomada mais intensa do crescimento no curto prazo.

Quando da comparação do Espírito Santo com outros estados da região Sudeste, é possível notar que, em termos de produtividade do trabalho, o estado apresentou um desempenho nitidamente superior no período anterior à crise financeira de 2008 (janeiro a agosto de 2008). Entretanto, quando se considera o período pós-crise (setembro de 2008 a maio de 2009), o Espírito Santo apresentou o pior desempenho dentre os estados analisados ${ }^{18}$.

No caso do período recente (2008/2009), o desempenho da produtividade do trabalho parece estar condicionado principalmente ao desempenho da produção industrial, tanto no caso estadual quanto no caso nacional.

Esses resultados devem ser vistos como uma primeira tentativa de compreensão da dinâmica inerente à produtividade do estado. Estudos futuros poderão vir a confirmar alguns dos resultados aqui reportados, assim como propor explicações detalhadas para os principais padrões empíricos descritos neste trabalho.

Em termos de pesquisa futura, ficam duas sugestões básicas. Em primeiro lugar, seria interessante verificar a robustez dos resultados obtidos quando do uso de microdados referentes às indústrias nacional e estaduais consideradas, nas linhas propostas por Bartelsman \& Doms (2000). Uma análise nesses moldes poderia ser útil no sentido de evitar problemas decorrentes de diferenças na composição dos indicadores utilizados, conforme citado acima.

Em segundo lugar, é possível que diferenças em termos de metodologia de construção de medidas de PTF possam vir a gerar distintos resultados da evolução dessa variável ao longo do tempo. Nesse sentido, fica a sugestão de elaboração de estudos que busquem verificar a robustez dos resultados apresentados a partir do uso de medidas construídas via metodologias distintas, conforme fazem Burnside, Eichenbaum \& Rebelo (1996), Paquet \& Robidoux (2001) e Magalhães (2010), por exemplo.

Dada a importância fundamental da produtividade para o crescimento e o desenvolvimento de uma economia, espera-se que a compreensão detalhada da evolução dessa variável possa constituir um fundamento básico para a formulação de políticas públicas que visem aumentar o bem-estar da sociedade.

18 Esse padrão empírico foi confirmado para períodos posteriores. De fato, a economia do Espírito Santo tende, em geral, a crescer acima da média nacional durante períodos de expansão, com o padrão inverso ocorrendo durante períodos de recessão. Ver, a esse respeito, Magalhães e Ribeiro (2009), Panorama Econômico (2010) e Magalhães e Toscano (2010). 


\section{Referências}

BARTELSMAN, E. J. \& DOMS, M. (2000) "Understanding productivity: lessons from longitudinal microdata.” Journal of Economic Literature 38 (3): 569-594.

BONELLI, R. \& FONSECA, R. (1998) "Ganhos de produtividade e eficiência: novos resultados para a economia brasileira.” Pesquisa e Planejamento Econômico 28 (2)

BURNSIDE, C.\& EICHENBAUM, M.\& REBELO, S. (1995)“Capital utilization and returns to scale”. NBER Macroeconomics Annual 67-110.

BURNSIDE, C. \& EICHENBAUM, M. \& REBELO, S. (1996) “Sectoral Solow residual”. European Economic Review 40 (4): 861-869.

GRILICHES, Zvi. (1996) "The discovery of the residual: a historical note”. Journal of Economic Literature 34 (1): 1324-1330.

HODRICK, R. \& PRESCOTT, E.C. (1997)“Post-War U.S. business cycles: a descriptive empirical investigation”. Journal of Money, Credit and Banking 29 (1): 1-16.

INDICADORES CONJUNTURAIS DA INDÚSTRIA - Produção. (2004) Série Relatórios Metodológicos 31, 2004.

KANCZUK, F. \& FARIAJr, F. (2000) “Ciclos reais para a indústria brasileira? Estudos Econômicos 47 (4): 335-350.

MAGALHÃES, M. A.(2010) "Resíduos de Solow industriais: um estudo empírico para o Brasil”. Análise Econômica.

MAGAlHÃES, M. A.\& RIBEIRO, A. P. L. (2009) “Ciclos de Negócios no Espírito Santo". Texto para Discussão 9. IJSN.

MAGALHÃES, M. A. \& TOSCANO, V. N. (2010) “Produtividade Industrial”, Resenha de Conjuntura. IJSN. Vários números.

PANORAMA ECONÔMICO (2010) Espírito Santo. IJSN. Vários números.

PAQUET, A. \& ROBIDOUX, B. (2001) "Issues on the measurement of the Solow residual and the testing of its exogeneity: evidence for Canada". Journal of Monetary Economics 47 (3): 595-612.

SOLOW, R.M. (1957) Technical change and the aggregate production function. The Review of Economics and Statistics 39 (3): 312-320.

Recebido em: 01 de março de 2010

Primeira resposta em: 18 de junho de 2010

Aceite em: 12 de agosto de 2010 


\section{Apêndice A: Estatísticas Descritivas e Gráficos das Variá- veis Utilizadas na Análise}

A Tabela A1 abaixo contém as estatísticas descritivas das principais variáveis analisadas neste trabalho.

TABELA A1. ESTATÍSTICAS DESCRITIVAS DAS VARIÁVEIS ANALISADAS

\begin{tabular}{|c|c|c|c|c|c|c|}
\hline & & Média & Mediana & Desvio-Padrão & Máximo & Mínimo \\
\hline \multirow{5}{*}{ Brasil } & Prod. Industrial & 109,70 & 108,90 & 12,43 & 138,29 & 86,69 \\
\hline & Horas Pagas & 101,53 & 101,08 & 2,91 & 109,25 & 95,02 \\
\hline & Energia Elétrica & $12.306 .425,74$ & 12.526.000, oo & $1.681 .748,74$ & 15.765.000,00 & $9.178 .000,00$ \\
\hline & Prod. Trabalho & 107,82 & 108,21 & 9,46 & 126,98 & 87,52 \\
\hline & Prod. Total dos Fatores & 111,83 & 112,22 & 5,87 & 124,19 & 94,52 \\
\hline \multirow{5}{*}{$\begin{array}{c}\text { Espírito } \\
\text { Santo }\end{array}$} & Prod. Industrial & 113,38 & 111,57 & 17,20 & 156,14 & 81,77 \\
\hline & Horas Pagas & 94,78 & 94,73 & 2,91 & 101,16 & 88,31 \\
\hline & Energia Elétrica & $173 \cdot 303,62$ & $197 \cdot 393,67$ & $76.789,62$ & $318.965,33$ & $68.993,10$ \\
\hline & Prod. Trabalho & 119,83 & 118,99 & 19,06 & 163,55 & 85,18 \\
\hline & Prod. Total dos Fatores & 168,83 & 152,73 & 44,43 & 237,41 & 98,28 \\
\hline \multirow{3}{*}{$\begin{array}{l}\text { Minas } \\
\text { Gerais }\end{array}$} & Prod. Industrial & 112,48 & 109,78 & 14,61 & 148,35 & 88,10 \\
\hline & Horas Pagas & 105,70 & 105,73 & 6,36 & 120,85 & 94,44 \\
\hline & Prod. Trabalho & 106,09 & 105,33 & 8,50 & 125,29 & 82,89 \\
\hline \multirow{3}{*}{ SãoPaulo } & Prod. Industrial & 112,67 & 110,27 & 14,97 & 147,82 & 83,59 \\
\hline & Horas Pagas & 101,84 & 101,18 & 4,65 & 112,60 & 93,33 \\
\hline & Prod. Trabalho & 110,30 & 110,40 & 10,52 & 131,79 & 85,23 \\
\hline \multirow{3}{*}{$\begin{array}{c}\text { Rio de } \\
\text { Janeiro }\end{array}$} & Prod. Industrial & 101,71 & 102,69 & 7,58 & 116,62 & 84,49 \\
\hline & Horas Pagas & 86,31 & 84,18 & 5,32 & 100,00 & 78,72 \\
\hline & Prod. Trabalho & 118,54 & 122,62 & 13,44 & 140,86 & 87,82 \\
\hline
\end{tabular}

Elaboração: Cálculos dos Autores.

FONTE: Pesquisa Industrial Mensal - Produção Física (PIM-PF), Pesquisa Industrial Mensal de Empregos e Salários (PIMES) (IBGE), Agência de Serviços Públicos de Energia do Estado do Espírito Santo (ASPE), Espírito Santo Centrais Elétricas S.A. (ESCELSA) e Eletrobrás. 
Os Gráficos A1-A3, por sua vez, abaixo descrevem a evolução temporal de cada uma das séries utilizadas na análise desenvolvida acima.

\section{GRÁFICO A1. VARIÁVEIS UTILIZADAS - BRASIL}
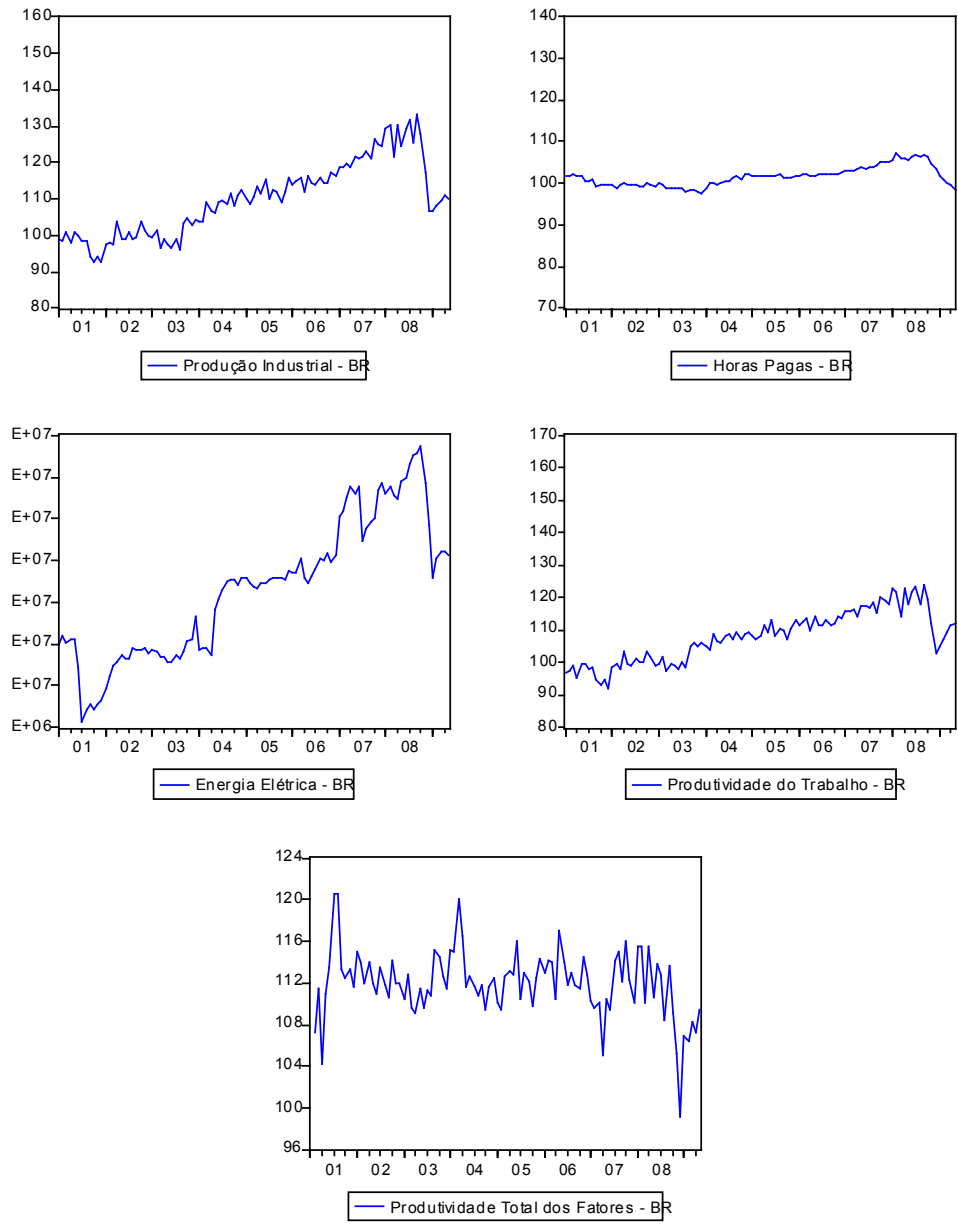

Elaboração: Cálculos dos Autores.

FONTE: Pesquisa Industrial Mensal - Produção Física (PIM-PF), Pesquisa Industrial Mensal de Empregos e Salários (PIMES) (IBGE) e Eletrobrás. 


\section{GRÁFICO A2. VARIÁVEIS UTILIZADAS - ESPIRITO SANTO}
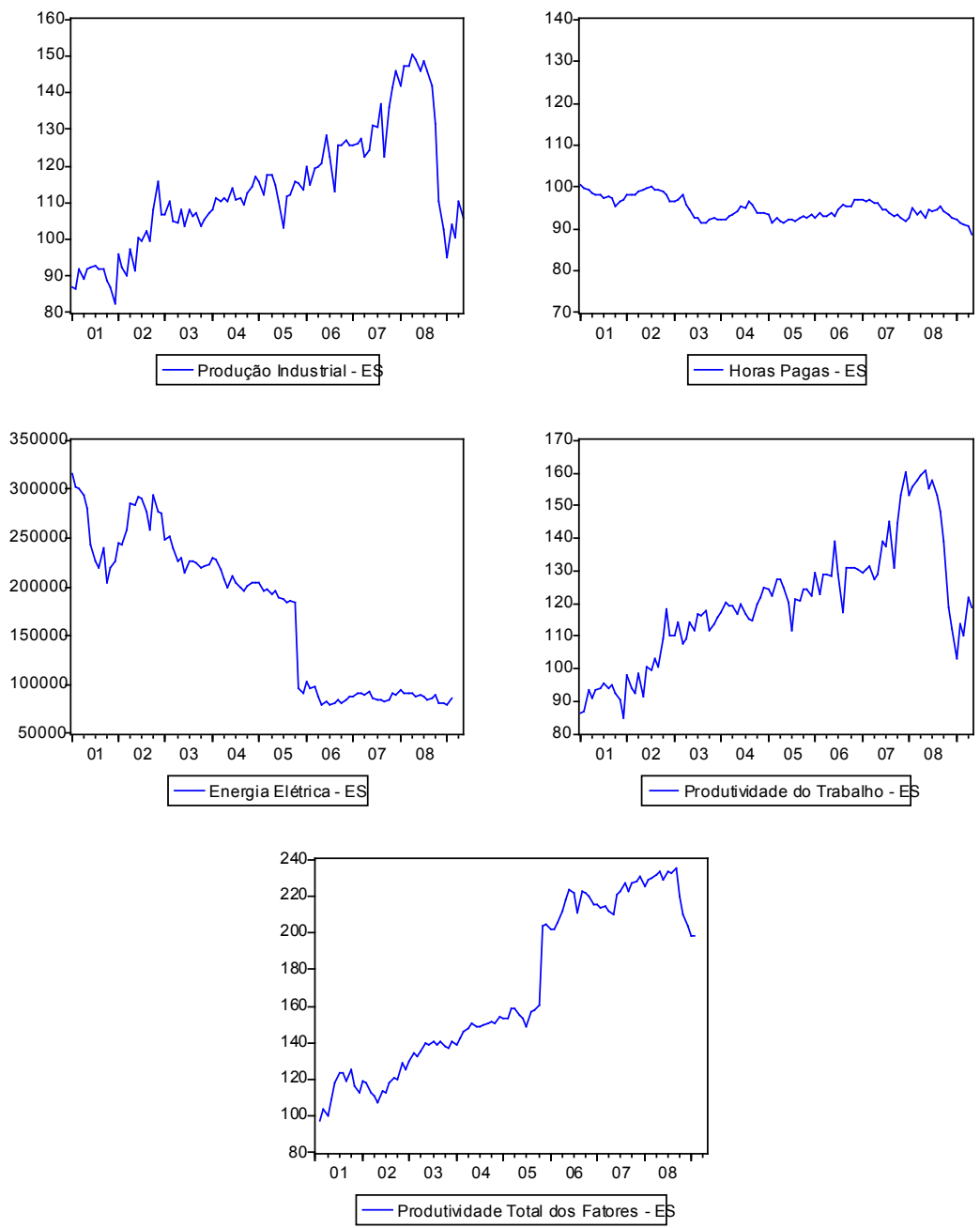

Elaboração: Cálculos dos Autores.

FONTE: Pesquisa Industrial Mensal - Produção Física (PIM-PF), Pesquisa Industrial Mensal de Empregos e Salários (PIMES) (IBGE), Agência de Serviços Públicos de Energia do Estado do Espírito Santo (ASPE), Espírito Santo Centrais Elétricas S.A. (ESCELSA) e Eletrobrás. 
GRÁFICO A3. VARIÁVEIS UTILIZADAS - MINAS GERAIS, RIO DE JANEIRO E SÃO PAULO
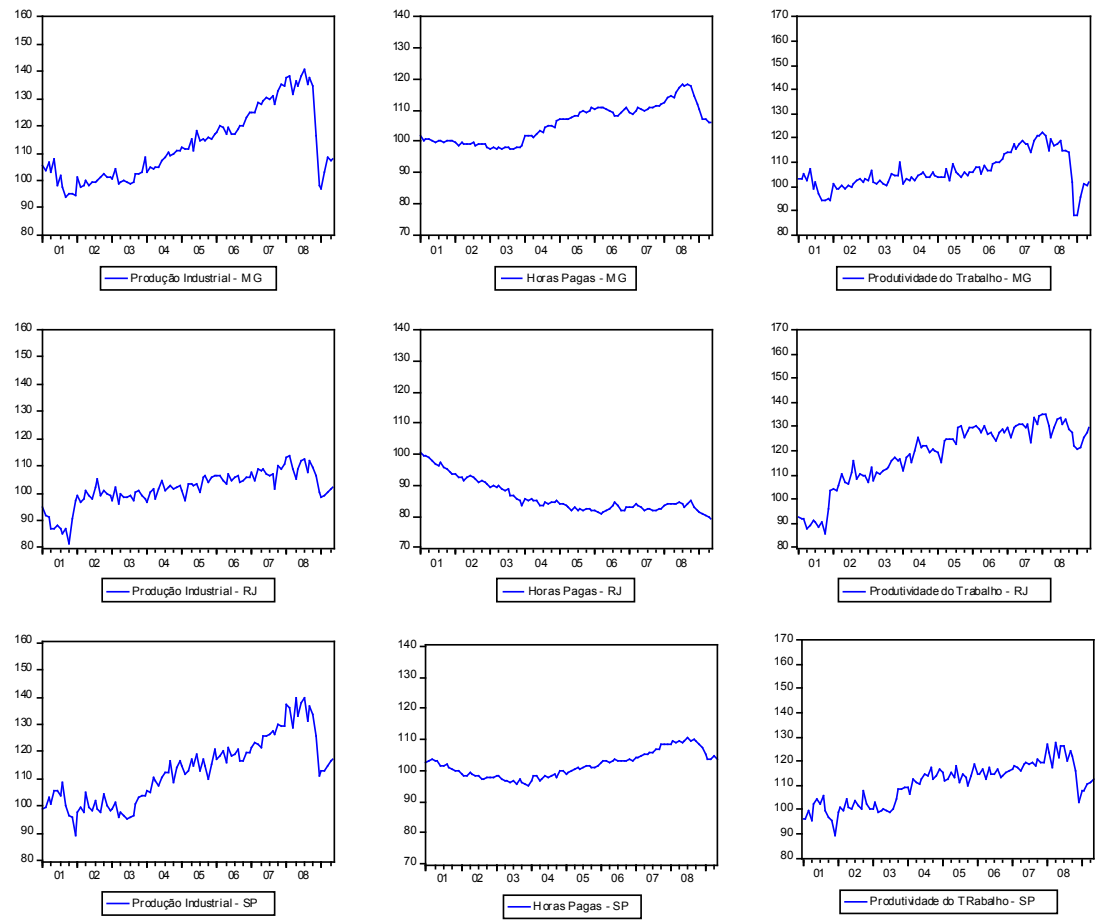

Elaboração: Cálculos dos Autores.

FONTE: Pesquisa Industrial Mensal - Produção Física (PIM-PF), Pesquisa Industrial Mensal de Empregos e Salários (PIMES) (IBGE) 


\section{Apêndice B: Filtro Hodrick-Prescott}

Um dos métodos utilizados para estacionarizar as séries estudadas neste trabalho foi o filtro Hodrick-Prescott (Hodrick \& Prescott 1997). Este é um filtro linear usado para a extração do componente de longo prazo de uma série econômica. A partir da subtração desse componente do logaritmo natural da série é possível a obtenção de seu componente cíclico.

Em particular, seja yt uma série temporal, com ytg e ytc correspondendo a seus componentes secular (longo prazo) e cíclico (curto prazo), respectivamente. Basicamente, o filtro Hodrick-Prescott corresponde à solução do seguinte problema de minimização:

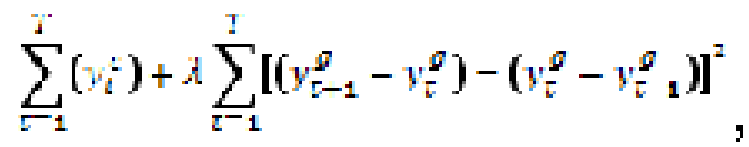

onde a expressão acima representa uma função perda, enquanto que o termo $\lambda$ equivale a um parâmetro que reflete a variância relativa do componente secular da série em comparação a seu componente cíclico, também conhecido como parâmetro de suavização. Na análise acima, foi empregado um valor de $\lambda$ igual a 14.400 , valor usualmente empregado no caso de dados mensais.

Por sua vez, o componente cíclico de uma série pode ser obtido a partir da seguinte operação:

$$
y_{c}^{r}-y_{t}-y_{i}^{a}
$$

Ou seja, a partir da subtração do componente secular do logaritmo natural da série, é possível a obtenção de seu componente cíclico. 